\title{
Limiting access to lethal means: applying the social ecological model for firearm suicide prevention
}

\author{
Adelyn Allchin, Vicka Chaplin, Joshua Horwitz
}

Educational Fund to Stop Gun Violence, Washington, DC, USA

\section{Correspondence to} Adelyn Allchin, Educational Fund to Stop Gun Violence, Washington, DC 20005, USA; aallchin@csgv.org;adelyn. allchin@gmail.com

Received 16 March 2018 Accepted 16 May 2018 Published Online First 25 June 2018
Check for updates

To cite: Allchin A, Chaplin V, Horwitz J. Inj Prev

2019:25:i44-i48.

\section{ABSTRACT}

This paper outlines a novel application of the social ecological model (SEM) for firearm suicide prevention. It focuses on four levels of intervention (societal, relationship, community and individual) to reduce access to firearms, a practical contributor to the capacity to attempt suicide, from individuals when they are at an elevated risk for suicide. There is substantive research linking easy access to firearms with an increased risk of firearm suicide, and suicide prevention interventions that address access to lethal means are critical components of a comprehensive suicide prevention strategy. Potential interventions using the SEM framework include: at the policy level—extreme risk laws, voluntary self-prohibition policies and policies that reduce the availability of firearms; at the community level—gun shop projects; at the relationship level—lethal means safety counselling; and at the individual level—safer storage. Taken together with upstream interventions, such as increased access to mental health services and substance use treatment, a multilevel approach for suicide prevention that addresses access to firearms can save lives.

\section{INTRODUCTION}

Suicide is the leading cause of violent death in the US, and one of the leading causes of death overall for Americans. Over the last decade, 399157 Americans died by suicide, of which 201 875approximately $50 \%$-died by firearm suicide. Firearm suicide rates have steadily increased, with an additional one person dying by firearm suicide per 100000 in 2016 compared with 2007 (age-adjusted firearm suicide rates per 100000 for 2016 and 2007 were 6.72 and 5.63, respectively). Males die by firearm suicide at a rate more than six times higher than females (age-adjusted firearm suicide rate for: males, 11.95 per 100 000; females, 1.93 per 100000 in 2016). The rate of firearm suicide among males rises with age, peaking at ages $\geq 85$ years (37.44 per 100000 in 2016). The rate of firearm suicide among females rises with age until peaking between the ages of 50 and 54 years $(3.55$ per 100000 in 2016), after which it declines with age. Additionally, there are differences in firearm suicide rates by race, with White males dying at the highest rate, followed by American-Indian and Alaskan Native, Black, and Asian and Pacific Islander males (age-adjusted firearm suicide rates were $13.54,8.69,5.50$ and 3.03 per 100000 in 2016, respectively). A similar pattern exists in females (age-adjusted firearm suicide rates were 2.28, 1.28, 0.79 and 0.37 per 100000 in 2016, respectively). ${ }^{1}$ The public health impact of suicide on families and communities is sizeable; suicide loss survivors are at an increased risk of suicide themselves, and bereavement can have adverse effects on mortality, mental health and social functioning. ${ }^{2}$

There are many risk factors for suicide, including substance ${ }^{3}$ and alcohol misuse, ${ }^{4}$ having a serious mental illness ${ }^{5}$ and experiencing a crisis in the last two weeks. ${ }^{6}$ Notably, there is substantive research linking easy access to firearms with an increased risk of firearm suicide. In places where household firearm ownership is more common, suicide rates-both overall and by firearms-are generally higher. ${ }^{7-9}$ One study examining gun ownership and state-wide suicide rates found that after controlling for covariates, gun ownership accounted for $92 \%$ of the variance between state-wide suicide rates. ${ }^{10}$ According to a meta-analysis of individual-level studies, access to a gun in the home increased the odds of suicide more than threefold. ${ }^{11}$ Indeed, suicide attempts with firearms are lethal nearly every time. Research found that approximately 9 out of 10 suicide attempts with firearms were lethal. ${ }^{12}$ Of the risk factors for suicide, access to firearms is relatively easily modifiable and thus provides a critical point for intervention. Notably, as some social environments are hostile to any efforts to mitigate firearms access, cultural barriers to implementation of such policies can be substantial. Focusing on time-limited, risk-based approaches such as those presented in this paper may mediate some of these barriers.

The Three-Step Theory of suicide posits that there are three steps through which an individual goes from suicidal ideation to attempt(s) and elucidates further how mitigating access to firearms (known as means restriction or means reduction) provides an important opportunity to reduce suicide risk. The theory outlines that an individual first must experience a combination of pain (typically psychological) and hopelessness in order for suicidal ideation to occur. Second, for those meeting the first set of criteria, a lack of connectedness allows ideation to escalate (conversely, bolstered connectedness serves as a protective factor). The third step from ideation to attempt is propelled by what the theory describes as capacity to attempt suicide, which is made up of dispositional, acquired and practical factors. ${ }^{13}$ Access to a firearm, given pain, hopelessness and a lack (or perceived lack) of connectedness, is a practical contributor to the capacity to attempt suicide. Attending to the third step of the model aligns with a recent shift of focus within firearm suicide prevention efforts to reducing access to firearms-focusing on the how, rather than the why, of suicide. ${ }^{14}$ 


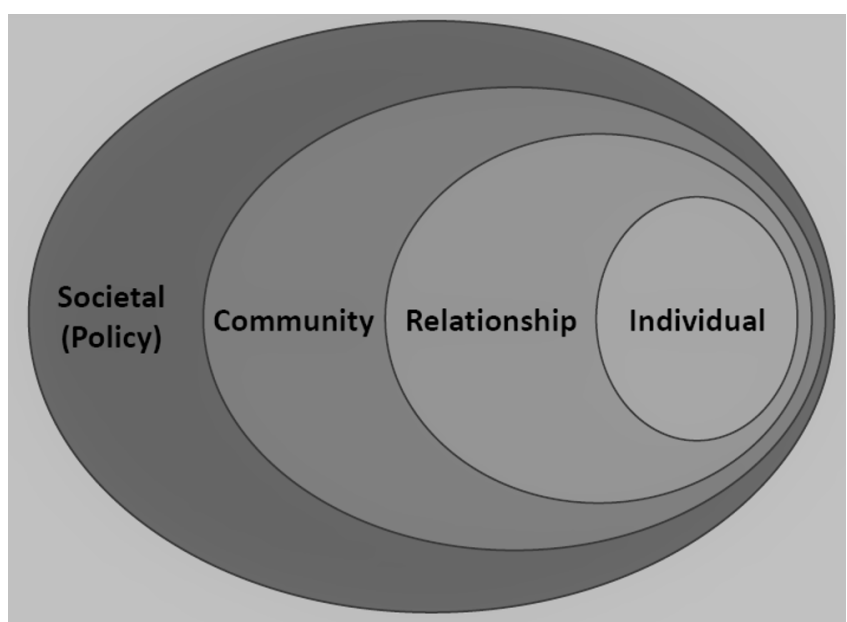

Figure 1 Social ecological model.

Barber and Miller's conceptual model on means restriction illustrates how reducing availability and accessibility of a practical contributor to the capacity to attempt suicide-such as firearms - can reduce suicide rates at the population level. According to the model, means restriction may lead to (1) substituting means (less common) or (2) temporarily or permanently delaying suicide attempts. If attempts are made with substituted means, they are generally less fatal, allowing time for suicidal crises to pass and leading to fewer suicides. Alternatively, if suicide attempts are delayed altogether without means substitution, the suicidal crises again may pass and result in fewer suicides. ${ }^{15}$ Through either path, temporarily reducing access to firearms for individuals who are at an elevated risk of suicide is likely to reduce suicide rates at the population level.

There are multiple ways to intervene to temporarily reduce access to firearms for individuals at risk for suicide. This paper outlines a novel application of the social ecological model (SEM) for firearm suicide prevention by focusing on four levels of intervention (societal, community, relationship and individual) to reduce access to firearms, a practical contributor to the capacity to attempt suicide, from individuals when they are at an elevated risk for suicide.

\section{SOCIAL ECOLOGICAL MODEL}

The SEM is a theoretically based framework developed to illustrate the interplay between individual and environmental factors in individual health and well-being (figure 1). Originating in systems theory and growing from early applications in human development, the model has been used extensively in public health as a way of providing context for why health problems occur and developing parallel approaches to health promotion and disease prevention. The SEM accounts for influence at and interaction among four levels: societal, community, relationship and individual; in turn, the public health approach relies on the application of interventions across all four levels.

The CDC developed an SEM-based framework for violence prevention that is widely used in violence prevention settings. ${ }^{16}$ The framework illustrates a range of risk and protective factors for experiencing and perpetrating violence. In the following paragraphs, the CDC's SEM-based framework for violence prevention is applied to the specific outcome of firearm suicide prevention via temporary separation of high-risk individuals from firearms, and potential strategies for intervention are briefly summarised. Traditional applications of the SEM outline

\begin{tabular}{|c|c|c|}
\hline Level & Intervention & Stakeholders involved \\
\hline \multirow[t]{3}{*}{ Societal } & $\begin{array}{l}\text { Extreme risk laws such as the } \\
\text { Extreme Risk Protection Order }\end{array}$ & $\begin{array}{l}\text { Policy-makers, law enforcement, } \\
\text { prosecutors, judges, family } \\
\text { members }\end{array}$ \\
\hline & Voluntary self-prohibition & $\begin{array}{l}\text { Policy-makers, law enforcement, } \\
\text { prosecutors, judges, individuals }\end{array}$ \\
\hline & $\begin{array}{l}\text { Other policies that reduce } \\
\text { availability of firearms }\end{array}$ & $\begin{array}{l}\text { Policy-makers, law enforcement, } \\
\text { prosecutors, judges }\end{array}$ \\
\hline Community & Gun Shop Project & Gun retailers, ranges and clubs \\
\hline \multirow[t]{2}{*}{ Relationship } & $\begin{array}{l}\text { Family/friends holding onto } \\
\text { firearms }\end{array}$ & Family members, friends \\
\hline & Lethal means safety counselling & Healthcare providers \\
\hline Individual & $\begin{array}{l}\text { Safer storage } \\
\text { Storing firearms and } \\
\text { ammunition separately } \\
\text { Giving family/friends key to } \\
\text { safe with firearms } \\
\text { Removing firearms from } \\
\text { home }\end{array}$ & Individuals \\
\hline
\end{tabular}

interventions that target risk and protective factors at all levels. In this application, interventions are developed at each level, but the goal is an individual one, to reduce access to firearms as lethal means of suicide. Moreover, many interventions proposed in the following paragraphs involve action across multiple levels. We begin broadly at the societal level and work towards the individual-level goal of increased means safety. Table 1 outlines examples of interventions at each level of the SEM.

\section{Societal level}

The broadest level of the SEM is the societal level, which explores how large social factors such as policy and culture influence health. Interventions for firearm suicide prevention at this level include developing and enacting policies that reduce access to firearms by high-risk individuals and shift cultural norms related to guns and suicide.

Recent state-level policy efforts to temporarily limit an at-risk individual's access to firearms have focused on extreme risk laws such as Extreme Risk Protection Orders with a nationwide surge of interest following in the wake of the tragic school shooting in Parkland, Florida on 14 February 2018. Early extreme risk laws were built upon by the Consortium for Risk-Based Firearm Policy with the development of Extreme Risk Protection Orders (also known as Gun Violence Restraining Orders, among other names). Extreme Risk Protection Orders allow law enforcement, and in some states family and household members, to petition a judge to temporarily limit an individual's access to firearms if they are at risk of harming themselves or others. ${ }^{17}{ }^{18}$ Individuals subject to Extreme Risk Protection Orders are temporarily prohibited from purchasing new firearms and are required to relinquish firearms in their possession while the order is in effect. $^{6}$

Emerging research suggests that extreme risk laws may be effective in saving lives. Specifically, a study examining 14 years of data from Connecticut's risk warrant law-a precursor to Extreme Risk Protection Orders that allows law enforcement to temporarily remove firearms through a warrant-based procedure-estimated that for every 10 to 20 risk warrants issued, one suicide was averted. ${ }^{19}$ As of June 2018, California, Connecticut, Florida, Indiana, Maryland, New Jersey, Oregon, Rhode Island, Vermont and Washington have extreme risk policies, ${ }^{20}$ and state legislators have introduced or plan to introduce extreme risk 
bills in approximately 26 additional states. ${ }^{21}$ Passing extreme risk policies is a first-step societal-level intervention; however, actions must follow at each level of the SEM to ultimately reduce access to lethal means. Stakeholders must collaborate for effective policy implementation, including developing processes for order service and relinquishment of firearms (community); families and law enforcement must recognise signs of risk and petition a court for an order (relationship); and the individuals must be educated on the terms of the order as well as resources that they may utilise to address the underlying causes of their dangerous behaviours (individual).

A complementary policy called a voluntary self-prohibition allows individuals to voluntarily place themselves on a do-notsell list, which would put their name into the National Instant Criminal Background Check System and prohibit them from purchasing firearms. One study surveying individuals at both inpatient and outpatient psychiatric clinics found that $46 \%$ of participants would put their name on such a list. Notably, individuals with access to a firearm were less likely to sign up for a do-not-sell list. ${ }^{22}$ In 2018, Washington became the first state to enact a voluntary self-prohibition law. ${ }^{23}$ Given the novelty of the policy, other states may look to data from Washington on uptake and efficacy before pursuing such legislation. Additionally, while the policy itself operates at the individual level, current efforts are necessary to pass such policies at the societal level and implement them at the community level.

Finally, any policies that generally reduce access to firearms by individuals who may be at risk for suicide are critical to prevent suicide. Such policies may include, but are not limited to, universal background checks including permit-to-purchase laws ${ }^{24}$ mandatory waiting periods ${ }^{25}$ and policies to support or incentivise interventions at other levels of the model (such as a policy that provides funding to train healthcare providers on lethal means safety counselling). Enacting evidence-based firearms violence prevention policies is a societal-level intervention that will enable and support actions at subsequent levels of the SEM while contributing to a shift in cultural norms towards (1) acknowledgement of the role of firearms in suicide; (2) acceptance of reducing firearms access as a viable suicide prevention strategy; and (3) a decrease in the ubiquitous nature of firearms in American society. The importance of such potential shifts in cultural norms cannot be overstated, as cultural barriers to efforts to mitigate firearms access among high-risk individuals are significant.

\section{Community level}

The community level of the SEM examines the social and physical environments in which an individual exists and how they are associated with risk and protective factors. Interventions for firearm suicide prevention at the community level influence the environment, such as by shifting organisational climate, processes and institutional policies. After laws are enacted at the societal level, they must be implemented successfully by stakeholders at the community level. Other interventions, however, begin at the community level.

An example of a community-level intervention to reduce access to firearms by individuals at risk for suicide is the Gun Shop Project. Developed out of a partnership between the New Hampshire Firearms Safety Coalition, the Means Matter programme at the Harvard T.H. Chan School of Public Health and other stakeholders, the Gun Shop Project builds on the partnership between firearms retailers, ranges, and clubs and public health experts. The Gun Shop Project provides retailers, instructors and customers of all experience levels with firearm suicide prevention educational materials. These include education on the elevated risk of suicide to the gun-owning community and strategies for prevention that allow gun owners to take an active role in suicide prevention among their peers. These are implemented through a variety of pathways, including educational events at shooting ranges, flyers for retail customers and materials encouraging retailers' increased awareness of potentially suicidal behaviour. Through this effort, an "11th Commandment of Gun Safety" was developed, encouraging temporary offsite storage of firearms when an individual is at elevated suicide risk. ${ }^{26}$ The Gun Shop Project has gained significant traction in recent years and is now being replicated in approximately two dozen states. ${ }^{27} 28$ Additionally, new partnerships are emerging, such as one between the American Foundation for Suicide Prevention and the National Shooting Sports Foundation that aims to distribute suicide prevention materials to gun owners. ${ }^{29}$

Intervening when an individual purchases a firearm is critical because their access to lethal means has increased. Access to a gun in the home increases suicide risk, ${ }^{11}$ and the gun purchase may be a symptom of suicidal crisis. One study showed risk of suicide is elevated immediately after purchasing a firearm and remains elevated for at least 6 years following the purchase. ${ }^{30}$ Educating gun owners about suicide risk is one area of common ground among gun violence prevention and gun rights advocates, and collaborations between gun owner groups and public health professionals that focus on putting time and space between at-risk individuals and firearms have the opportunity to save lives. $^{31}$

\section{Relationship level}

The SEM's relationship (interpersonal) level explores the close relationships that may influence an individual's risk, including those with family, friends and other individuals. For firearm suicide prevention, the relationship level encourages engagement and support by other individuals in the temporary separation of firearms from the at-risk individual. At this level, those close to an at-risk individual may intervene by applying a tool described in the societal or community levels, such as petitioning for an Extreme Risk Protection Order. While not all interventions at the relationship level originate in other levels, they will contribute to societal-level cultural shifts around the acceptability of discussions about the risks of firearms and reducing access to lethal means.

Gun storage out of the home provides a safer degree of separation than storage in the home. Friends or family who recognise that a loved one may be at risk may intervene and offer to store the at-risk individual's firearms for the duration of the crisis, if they can do so safely. If the individual at risk is a child or other individual who is not a gun owner but is exposed to them at home, a parent or other household member may choose to temporarily store their own guns outside of the home. One study examining firearm suicides among adolescents at six National Violent Injury Statistics System sites found that $82 \%$ of adolescents used firearms owned by family members among cases when information was available. ${ }^{32}$ As such, it is critical to address not just firearm ownership among adolescent populations, but firearms access via family members. Importantly, friends and family members should be aware of their state's laws to ensure that proper steps are taken when temporarily transferring a firearm ${ }^{33}$ as well as the risks associated with firearms possession as outlined in this paper. Options for safer storage 
of firearms are discussed in further detail under the individual level of the model.

In addition to family members and friends, healthcare providers have an important opportunity to engage in firearm suicide prevention at the relationship level by providing lethal means safety counselling to patients-or parents of paediatric patients-who may be at risk. Lethal means safety counselling occurs when healthcare providers ascertain if an at-risk individual has access to lethal means of suicide and work with the individual and their family or friends to reduce access until the risk of suicide decreases. ${ }^{34}$ Evidence suggests that individuals who receive counselling by physicians are significantly more likely to make safe changes in firearms storage practices than those who do not receive such counselling, ${ }^{35} 36$ yet a study of patients seen in the emergency room who had a positive suicide risk screen found that only $18 \%$ had documentation in their medical charts indicating they had received an assessment of lethal means access. ${ }^{37}$ This is not surprising: despite recommendations from groups like the American Academy of Pediatrics and Consortium for Risk-Based Firearm Policy for physicians to provide counselling, ${ }^{34} 38$ few providers are actually trained on how to provide lethal means safety counselling. ${ }^{39-44}$ However, efforts to train providers and create materials are underway, as affirmed by the newly updated policy from the American Medical Association which states they will "develop state-specific guidance for physicians on how to counsel patients to reduce their risk for firearm-related injury or death, including guidance on when and how to ask sensitive questions about firearm ownership, access, and use, and clarification on the circumstances under which physicians are permitted or may be required to disclose the content of such conversations to family members, law enforcement, or other third parties." ${ }^{45}$ Institutionalising such trainings is a community-level process that would enhance this relationship-level intervention.

\section{Individual level}

The individual (intrapersonal) level of the SEM relates to how biological and personal history factors affect an individual's risk for violence. Prevention efforts at this level address those factors, typically through education. In this context, access to firearms-defined by gun ownership, access to firearms in the household and firearms storage-is the critical personal history factor. Easy access to firearms increases the risk an individual will die by suicide; ${ }^{11}$ as such, interventions at the individual level should educate individuals, particularly those at high risk such as middle-aged and older males ${ }^{1}$ (thus also addressing biological factors of age and sex), about why it is important to separate oneself from lethal means.

One prevention strategy at the individual level is safer firearms storage. Safer storage mitigates access to firearms by the owner and other individuals-such as children and adolescents-in the shared environment and can be achieved through different ways. ${ }^{46}$ For example, within the home, individuals may choose to use trigger locks alone or in combination with a gun safe or to store their firearms separately from their ammunition, both in locked gun safes. To reduce access further, the gun owner may give a friend or family member the combination or key to the safe.

Storing firearms outside of the home is the safest option when an individual is at increased risk for suicide and has been recommended by healthcare providers and healthcare researchers. ${ }^{152747}$ Individuals may choose to voluntarily relinquish their firearms to friends or family members, a federally licensed firearms dealer or a local police department when they know they are at risk for harming themselves. However, a survey of gun retailers found that more than $60 \%$ of retailers were concerned about knowing when it was safe to return the firearm, and efforts are needed to address their concerns and provide clarity. ${ }^{48}$ While initiated by the individual, these storage options are reinforced or made available by interventions at other levels of the SEM framework.

\section{LIMITATIONS}

The programmes and policies previously described have a strong theoretical basis, but not all have sufficient evidence available regarding their efficacy. As more evidence-based policies such as extreme risk laws are implemented, evaluation is critical to measure their effects. More research is needed on lethal means safety counselling to understand what the best methods for counselling are to create behavioural change, how long these new behaviours last for and how effective it is generally as a tool for reducing firearm suicide. More research is needed to elucidate what additional interventions can be used at each level of the SEM to reduce access to firearms to prevent suicide. Interventions should be rigorously evaluated to determine how effective they are at reducing firearm suicide and if their effectiveness varies among different populations or between rural, suburban and urban settings. Additionally, research is needed to better understand how interactions between interventions at each level may amplify-or harm-firearm suicide prevention efforts. Despite limited research on available interventions and potential cultural barriers to their implementation, there is strong evidence that temporarily reducing firearms access to at-risk individuals can save lives.

\section{CONCLUSION}

Interventions at multiple levels of the SEM that address an individual's access to firearms when they are at risk for suicide is a critical component of a comprehensive suicide prevention strategy. A broad range of stakeholders, including individuals, friends and family members, healthcare providers, local organisations and businesses, and state and federal legislators, can all contribute to interventions that reduce firearm suicide. Taken together with upstream interventions, such as increased access to mental healthcare and substance use treatment, a multilevel approach addressing access to firearms has the opportunity to save lives.

Contributors $A A, V C$, and $J H$ had the idea for the manuscript. AA and VC performed the literature review, drafted the manuscript and revised the manuscript. AA is the guarantor. JH provided guidance and revised the draft manuscript.

Funding Support for this research was provided by the Hope and Heal Fund. Competing interests None declared.

Patient consent Not required.

Provenance and peer review Not commissioned; externally peer reviewed.

(c) Author(s) (or their employer(s)) 2019. No commercial re-use. See rights and permissions. Published by BMJ.

\section{REFERENCES}

1. National Center for Injury Prevention and Control CDC. 2007-2016 US firearm suicide deaths and rates per 100,000. Fatal injury reports. 2018. http://www.cdc.gov/injury/ wisqars/fatal.html (accessed 26 Jan 2018).

2. Pitman A, Osborn D, King M, et al. Effects of suicide bereavement on mental health and suicide risk. Lancet Psychiatry 2014;1:86-94.

3. Harris EC, Barraclough B. Suicide as an outcome for mental disorders. A meta-analysis. Br J Psychiatry 1997;170(MAR):205-28.

4. Conner KR, Huguet N, Caetano R, et al. Acute use of alcohol and methods of suicide in a US national sample. Am J Public Health 2014;104:171-8. 
5. Li Z, Page A, Martin G, et al. Attributable risk of psychiatric and socio-economic factors for suicide from individual-level, population-based studies: a systematic review. Soc Sci Med 2011;72:608-16.

6. Kalesan B, Sampson LA, Zuo Y, et al. Sex and age modify the relationship between life circumstances and use of a firearm in suicide deaths across 17 U.S. states. J Affect Disord 2018;236:105-11.

7. Miller M, Hemenway $D$. The relationship between firearms and suicide: A review of the literature. Aggress Violent Behav 1999:4:59-75.

8. Dahlberg LL, Ikeda RM, Kresnow MJ. Guns in the home and risk of a violent death in the home: findings from a national study. Am J Epidemiol 2004;160:929-

9. Siegel $M$, Rothman EF. Firearm ownership and suicide rates among US men and women, 1981-2013. Am J Public Health 2016;106:1316-22.

10. Anestis MD, Houtsma C. The Association between gun ownership and statewide overall suicide rates. Suicide Life Threat Behav 2018;48:204-17.

11. Anglemyer A, Horvath $T$, Rutherford $G$. The accessibility of firearms and risk for suicide and homicide victimization among household members: a systematic review and meta-analysis. Ann Intern Med 2014;160:101-13.

12. Azrael $D$, Miller M. Reducing suicide without affecting underlying mental health: theoretical underpinnings and a review of the evidence base linking the availability of lethal means and suicide. In: The International Handbook of Suicide Prevention. 2nd edn, 2016:637-62.

13. Klonsky ED, May AM. The three-step theory (3ST): a new theory of suicide rooted in the "ideation-to-action" framework. Int J Cogn Ther 2015;8:114-29.

14. Swanson JW, Bonnie RJ, Appelbaum PS. Getting serious about reducing suicide: More "How" and Less "Why". JAMA 2015;314:2229-303.

15. Barber CW, Miller MJ. Reducing a suicidal person's access to lethal means of suicide: a research agenda. Am J Prev Med 2014;47(3 Suppl 2):S264-S272.

16. Krug EG, Dahlberg LL, Mercy JA. World Report on Violence and Health. Geneva, 2002.

17. McGinty EE, Frattaroli S, Appelbaum PS, et al. Using research evidence to reframe the policy debate around mental illness and guns: process and recommendations. Am J Public Health 2014;104:e22-e26.

18. Vernick JS, Alcorn T, Horwitz J. Background checks for all gun buyers and gun violence restraining orders: state efforts to keep guns from high-risk persons. J Law Med Ethics 2017;45(1_suppl):98-102.

19. Swanson JW, Norko MA, HJU L, et al. Implementation and effectiveness of connecticut's risk-based gun removal law: does it prevent suicides ? Law Contemp Prob/ 1999;2016:14. https://scholarship.law.duke.edu/cgi/viewcontent.cgi? referer=\& httpsredir $=1 \&$ article $=4830 \&$ context $=\mid \mathrm{cp}$.

20. Cal. Penal Code § 18100-18205 (2018); Conn. Gen. Stat. § 29-38c (2018); Fla. Stat. $\S 790.401$ (2018); Ind. Code Ann. § 35-47-14-1 - 35-47-14-10 (2018); Md. Code Ann. §§ 5-601 - 5-610 (2018); Assemb. 1217, 218th Leg., Reg. Sess. (N.J. 2018); Or. Rev. Stat. §§ 166.525-166.543 (2018); R.I. Gen. Laws Ann. §§ 8-8.3-1 - 8-8.314 (2018); Vt. Stat. Ann. tit. 13, §§ 4051-4063 (2018); Wash. Rev. Code Ann. § 7.94.010-7.94.900 (2018).

21. Kavanagh B. State lawmakers announce 30 -state push for commonsense laws to prevent individuals likely to harm themselves or others from accessing guns. 2018. https://www.nysenate.gov/newsroom/press-releases/brian-kavanagh/statelawmakers-announce-30-state-push-commonsense-laws

22. Vars FE, McCullumsmith $C B$, Shelton $R C$, et al. Willingness of mentally ill individuals to sign up for a novel proposal to prevent firearm suicide. Suicide Life Threat Behav 2017; 47:483-92.

23. S. 5553, 65th Leg., Reg. Sess. (Wash. 2018).

24. Crifasi CK, Meyers JS, Vernick JS, et al. Effects of changes in permit-topurchase handgun laws in Connecticut and Missouri on suicide rates. Prev Med 2015;79:43-9.

25. Anestis MD, Anestis JC. Suicide rates and state laws regulating access and exposure to handguns. Am J Public Health 2015;105:2049-58.
26. Daley J. Colorado gun shops work together to prevent suicides. all things considered, national public radio in partnership with colorado public radio and kaiser health news. 2016. http://www.npr.org/sections/health-shots/2016/09/02/492144056/coloradogun-shops-work-together-to-prevent-suicides

27. Vriniotis $M$, Barber $C$, Frank $E$, et al. New Hampshire firearm safety coalition. A suicide prevention campaign for firearm dealers in New Hampshire. Suicide Life Threat Behav 2015;45:157-63.

28. Barber C, Demicco R. Common ground: reducing gun access. suicide prevention resource center. 2017. http://www.sprc.org/video/reducing-access-to-means

29. Sanetti SL. AFSP and NSSF: tremendous potential to save lives. https://afsp.org/afspnssf-tremendous-potential-save-lives/

30. Wintemute GJ, Parham CA, Beaumont JJ, et al. Mortality among recent purchasers of handguns. N Engl J Med 1999;341:1583-9.

31. Barber C, Frank E, Demicco R. Reducing suicides through partnerships between health professionals and gun owner groups-beyond docs vs glocks. JAMA Intern Med 2017; 177:5-6

32. Johnson RM, Barber C, Azrael D, et al. Who are the owners of firearms used in adolescent suicides? Suicide Life Threat Behav 2010;40:609-11.

33. McCourt AD, Vernick JS, Betz ME, et al. Temporary transfer of firearms from the home to prevent suicide: Legal obstacles and recommendations. JAMA Intern Med 2017;177:96-101.

34. Allchin A, Chaplin V. Breaking Through Barriers: The Emerging Role of Healthcare Provider Training Programs in Firearm Suicide Prevention. Washington, D.C, 2017. https://efsgv.org/wp-content/uploads/2017/09/Breaking-through-Barriers-September2017-Consortium-for-Risk-Based-Firearm-Policy-FINAL.pdf

35. Albright TL, Burge SK. Improving firearm storage habits: impact of brief office counseling by family physicians. J Am Board Fam Pract 2003;16:40-6.

36. Barkin SL, Finch SA, Ip EH, , et al. Is office-based counseling about media use, timeouts, and firearm storage effective? Results from a cluster-randomized, controlled trial. Pediatrics 2008;122:e15-e25.

37. Betz ME, Kautzman M, Segal DL, et al. Frequency of lethal means assessment among emergency department patients with a positive suicide risk screen. Psychiatry Res 2017;260:30-5.

38. Shain B. Committee on Adolescence. Suicide and suicide attempts in adolescents. Pediatrics 2016:138:e20161420.

39. Olson LM, Christoffel KK, O'Connor KG. Pediatricians' involvement in gun injury prevention. Inj Prev 2007;13:99-104

40. Everett SA, Price JH, Bedell AW, et al. Family practice physicians' firearm safety counseling beliefs and behaviors. J Community Health 1997;22:313-24.

41. Price JH, Kinnison A, Dake JA, et al. Psychiatrists' practices and perceptions regarding anticipatory guidance on firearms. Am J Prev Med 2007;33:370-3.

42. Slovak K, Brewer TW, Carlson K. Client firearm assessment and safety counseling: the role of social workers. Soc Work 2008;53:358-66.

43. Traylor A, Price JH, Telljohann SK, et al. Clinical psychologists' firearm risk management perceptions and practices. J Community Health 2010;35:60-7.

44. Price JH, Thompson A, Khubchandani J, et al. Perceived roles of emergency department physicians regarding anticipatory guidance on firearm safety. J Emerg Med 2013:44:1007-16.

45. Firearm Safety Counseling in Physician-Led Health Care Teams H-145.976: American Medical Association.

46. Wintemute GJ, Betz ME, Ranney ML. Yes, you can: physicians, patients, and firearms. Ann Intern Med 2016;165:205-13.

47. Grossman DC, Mueller BA, Riedy C, et al. Gun storage practices and risk of youth suicide and unintentional firearm injuries. JAMA 2005;293:707-14.

48. Pierpoint LA, Tung GJ, Brooks-Russell A, et al. Gun retailers as storage partners for suicide prevention: what barriers need to be overcome? Inj Prev 2018:injuryprev-2017-042700. 